\title{
Preparation and Solid State Characterization of 1,2,3,5-Diselenadiazolyl $\left[\mathrm{HCN}_{2} \mathrm{Se}_{2}\right]^{\circ}$
}

\author{
A. Wallace Cordes, ${ }^{a}$ Sivert H. Glarum, ${ }^{b}$ Robert C. Haddon, ${ }^{b}$ Randal Hallford, ${ }^{a}$ Robin G. Hicks, ${ }^{c}$ \\ Dietmar K. Kennepohl, ${ }^{c}$ Richard T. Oakley, ${ }^{c}$ Thomas T. M. Palstra ${ }^{b}$ and Syrona R. Scott ${ }^{a}$ \\ a Department of Chemistry and Biochemistry, University of Arkansas, Fayetteville, Arkansas 72701, USA \\ b AT \& T Bell Laboratories, 600 Mountain Avenue, Murray Hill, New Jersey 07974, USA \\ c Guelph-Waterloo Centre for Graduate Work in Chemistry, Guelph Campus, Department of Chemistry and \\ Biochemistry, University of Guelph, Guelph, Ontario N1G 2W1, Canada
}

The reaction of $N, N_{1} N^{\prime}$-tris(trimethylsilyl)formamidine with $\mathrm{SeCl}_{2}$ affords 1,2,3,5-diselenadiazolium chloride, which can be reduced with triphenylantimony to the corresponding diselenadiazolyl radical $\left[\mathrm{HCN}_{2} \mathrm{Se}_{2}\right]^{*}$; the solid state structure and conductivity of the dimer $\left[\mathrm{HCN}_{2} \mathrm{Se}_{2}\right]_{2}$ are reported.

Interest in the design of molecular conductors based on neutral $\pi$-radicals has prompted the study of heterocyclic thiazyl and selenazyl radicals, in particular derivatives of 1,2,3,5-dithia- and diselena-diazolyl. ${ }^{\prime}$ Several systems with different substituents in the 4-position have been characterized in the solid state. ${ }^{2.3}$ Structure-conductivity correlations based on several selenium derivatives ${ }^{4-6}$ indicate that the size of the 4-substituent plays an important role in determining the number and magnitude of close intermolecular interactions, and hence band dispersion. ${ }^{7}$ In the belief that smaller organic substituents should lead to more densely-packed structures with narrower band gaps, we have prepared the prototypal diselenadiazolyl heterocycle $\mathbf{1}$, in which the organic group has been removed entirely. The solid state characterization of the dimer is also described.

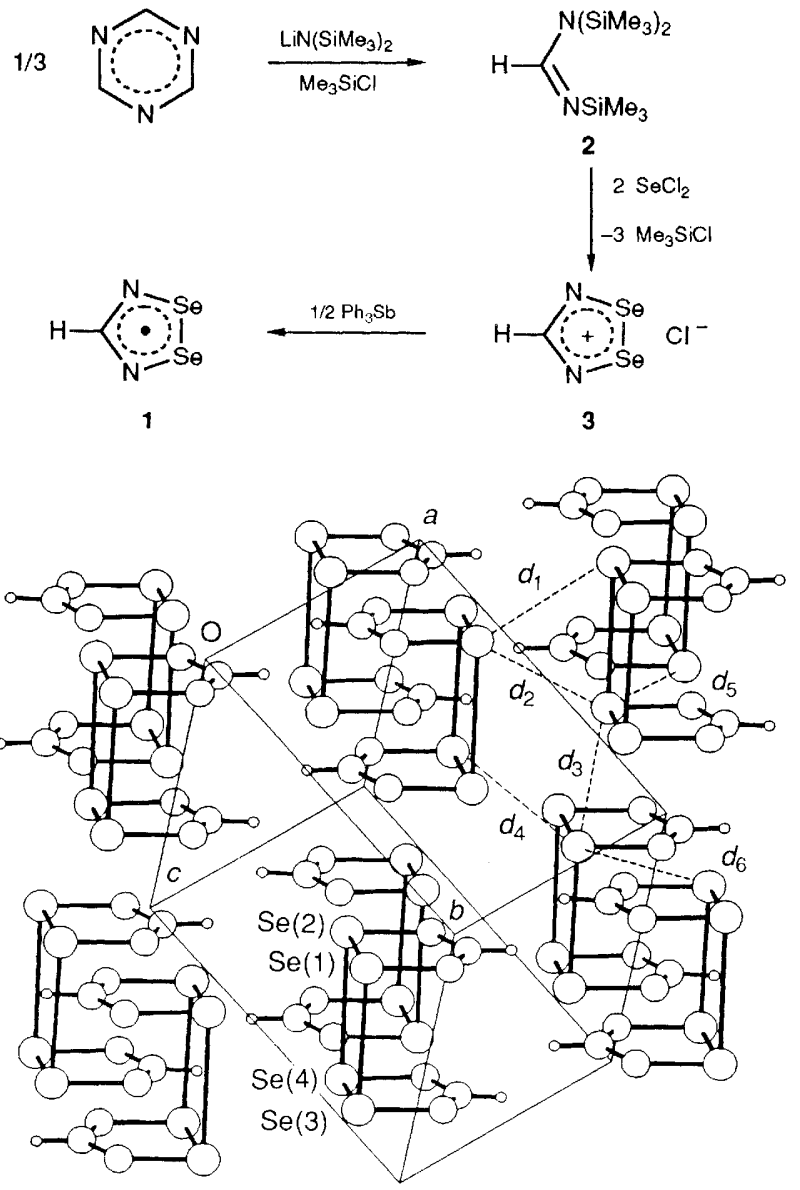

Fig. 1 General view of the crystal structure of $\left[\mathrm{HCN}_{2} \mathrm{Se}_{2}\right]_{2}$, showing head-over-tail stacking of dimers. Intradimer distances $(\AA)$ are $\mathrm{Se}(1)-\mathrm{Se}(2)$ 2.329(4): $\mathrm{Se}(3)-\mathrm{Se}(4)$ 2.322(4): $\mathrm{Se}(1)-\mathrm{Se}(3)$ 3.215(3); $\mathrm{Se}(2)-\mathrm{Se}(4), 3.345(3)$; interdimer contacts $(\AA)$ are $d_{1}, \mathrm{Se}(4) \cdots \operatorname{Se}\left(2^{\prime}\right)$ 3.382(4); $d_{2}, \operatorname{Se}(4) \cdots \operatorname{Se}\left(4^{\prime}\right), 3.376(5) ; d_{3}, \operatorname{Se}(1) \cdots \operatorname{Se}\left(4^{\prime}\right), 4.049(4) ; d_{4}$, $\mathrm{Se}(1) \cdots \operatorname{Se}\left(1^{\prime}\right), \quad 3.445(5) ; \quad d_{5}, \quad \operatorname{Se}(2) \cdots \operatorname{Se}\left(4^{\prime}\right) \quad 3.724(4) ; \quad d_{6}$ $\operatorname{Se}(1) \cdots \operatorname{Se}\left(3^{\prime}\right), 3.774(5)$.
Our primary synthetic route to both $1,2,3,5$-dithia- and diselena-diazolium cations has involved the condensation of persilylated amidines $\mathrm{RCN}\left(\mathrm{SiMe}_{3}\right)_{2} \mathrm{NSiMe}_{3}$ with $\mathrm{ECl}_{2}(\mathrm{E}=\mathrm{S}$, $\mathrm{Se})$. However, the method of preparation of the amidines, the addition of $\mathrm{LiN}(\mathrm{SiMe})_{2}$ to a nitrile $\mathrm{RCN},{ }^{8}$ appears to be limited to aryl nitriles. We have now discovered that the parent compound $N, N, N^{\prime}$-tris(trimethylsilyl)formamidine $\mathbf{2}$ can be conveniently generated by the reaction of $\mathrm{LiN}$ $\left(\mathrm{SiMe}_{3}\right)_{2} \cdot \mathrm{Et}_{2} \mathrm{O}(54.1 \mathrm{~g}, 224 \mathrm{mmol})$ with $1,3,5$-triazine $(6.2 \mathrm{~g}$, $76 \mathrm{mmol}$ ) in $200 \mathrm{ml}$ toluene, followed by treatment of the intermediate lithiated amidine with $\mathrm{Me}_{3} \mathrm{SiCl}(25.7 \mathrm{~g}, 237$ mmol); 2 distils at $35^{\circ} \mathrm{C} / 10^{-2}$ Torr $(1$ Torr $=133.3 \mathrm{~Pa}$; yield, $41.5 \mathrm{~g}, 66 \%) ;{ }^{1} \mathrm{H} \mathrm{NMR}, \delta\left(\mathrm{CDCl}_{3}\right) 7.96(\mathrm{~s}, 1 \mathrm{H}, \mathrm{HC}), 0.16(\mathrm{~s}$, $\left.27 \mathrm{H}, \mathrm{Me}_{3} \mathrm{Si}\right)$. Addition of $2(6.38 \mathrm{~g}, 24 \mathrm{mmol})$ to selenium dichloride $(3.60 \mathrm{~g}, 24 \mathrm{mmol}$, prepared in situ from Se and $\left.\mathrm{SeCl}_{4}\right)$ in acetonitrile $(140 \mathrm{ml})$ affords the diselenadiazolium cation $3(\mathrm{E}=\mathrm{Se})$ as a reddish-brown powder in virtually quantitative yield. Reduction of this crude salt (1.27 g, 5.4 $\mathrm{mmol})$ with triphenylantimony $(0.96 \mathrm{~g}, 2.7 \mathrm{mmol})$ in acetonitrile $(20 \mathrm{ml})$ yields $1,2,3,5$-diselenadiazolyl $\mathbf{1}$, which can be purified by sublimation at $50^{\circ} \mathrm{C} / 10^{-3}$ Torr as lustrous greyblack needles $(0.56 \mathrm{~g}, 52 \%)$; decomp. $>100^{\circ} \mathrm{C}$; MS $(70 \mathrm{eV})$ $\mathrm{m} / \mathrm{z} 201\left(\mathrm{M}^{+}, 40 \%\right), 174\left(\mathrm{Se}_{2} \mathrm{~N}^{+}, 95 \%\right), 160\left(\mathrm{Se}_{2}{ }^{+}, 100 \%\right)$ $107\left(\mathrm{HCNSe}^{+}, 8 \%\right), 94\left(\mathrm{SeN}^{+}, 20 \%\right), 80\left(\mathrm{Se}^{+}, 50 \%\right)$. The ESR signal (in $\mathrm{CH}_{2} \mathrm{Cl}_{2}, 295 \mathrm{~K}$ ) of 1 consists of a featureless singlet, with $g=2.041$.

The crystal structure of the dimer of 1 has been determined by X-ray diffraction. $\dagger$ The structure consists of antiparallel arrays of cofacial dimers $\left[\mathrm{HCN}_{2} \mathrm{Se}_{2}\right]_{2} ;$ Fig. 1 provides a general view of the structure, defines the interdimer contacts $d_{1}-d_{6}$, and illustrates the head-over-tail packing of dimers. All intramolecular bond lengths and angles are nominal, but the two interannular contacts $\operatorname{Se}(1) \cdots \operatorname{Se}(3) \quad[3.215(3) \AA]$ and $\operatorname{Se}(2) \cdots \operatorname{Se}(4) \quad[3.345(3) \AA]$ are notably different (cf. $\left[\mathrm{PhCN}_{2} \mathrm{Se}_{2}\right]_{2}{ }^{3}$ ). The interdimer Se $\cdots$ Se contacts $d_{5}$ and $d_{6}$ are well within the van der Waals separation, ${ }^{9}$ and generate a strong network of lateral interactions. These lateral contacts help lace together interpenetrating spiral-like columns of dimers, one of which is shown in Fig. 2. Within these columns, which run parallel to $z$, there are many close Se...Se contacts. The interactions $d_{1}, d_{2}$ and $d_{4}$, which connect dimer units that approach one another in a side-slipped head-on manner, are all exceptionally short. The final contact $d_{3}$ runs almost parallel to $z$ and connects (somewhat loosely) rings in a corner-to-corner fashion.

+ Crystal data for 1 : $\mathrm{Se}_{2} \mathrm{~N}_{2} \mathrm{CH}, M=199.0$, triclinic, $P \overline{\mathrm{I}}, a=6.279(4)$ ). $b=7.961(6), c=8.012(5) \AA, \alpha=69.94(6), \beta=88.98(5), \gamma=$ $84.03(6)^{\circ}, V=374.1(4) \AA^{3}, Z=4, D_{c}=3.53 \mathrm{~g} \mathrm{~cm}^{-3}, \mu=19.4 \mathrm{~mm}^{-1}$. Data were collected with an Enraf-Nonius CAD-4 automated diffractometer, with graphite-monochromated Mo-K $\alpha$-radiation ( $\lambda$ $=0.71073 \AA$ ) using $\theta-2 \theta$ scans to a $2 \theta_{\max }=50^{\circ}$. The structure was solved by direct methods (SHELX) and refined by full-matrix least-squares analysis which minimized $\Sigma w(\Delta F)^{2} .81$ Parameters were refined using 700 unique observed reflections $[I>2.5 \sigma(I)]$ to give $R=$ 0.048 and $R_{\mathrm{w}}=0.050$. Atomic coordinates, bond lengths and angles, and thermal parameters have been deposited at the Cambridge Data Centre. See Notice to Authors, Issue No. 1. 


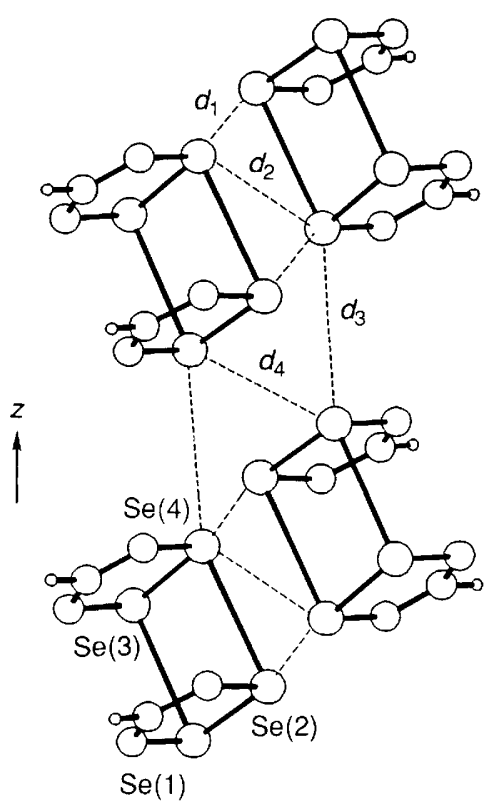

Fig. 2 Columns of dimers running parallel to $z$

In the solid state the dimer $\left[\mathrm{HCN}_{2} \mathrm{Se}_{2}\right]_{2}$ is diamagnetic, with a residual spin density, estimated by ESR, of $0.01 \%$. The material exhibits a single crystal conductivity of $7 \times 10^{-6} \mathrm{~S}$ $\mathrm{cm}^{-1}$, a value which is at least three orders of magnitude higher than that seen in other monofunctional selenium-based radical dimers. ${ }^{4}$ Collectively the interdimer Se $\cdots$ Se contacts, indicated above, generate a structure in which dispersion of the valence and conduction bands is more pronounced than in organo-substituted materials.
We thank the NSERC of Canada, the NSF and the State of Arkansas for financial support.

Received, 13th May 1992; Com. 2/02481K

\section{References}

1 A. W. Cordes, R. C. Haddon and R. T. Oakley, in The Chemistry of Inorganic Ring Systems, ed. R. Steudel, Elsevier, Amsterdam, 1992, p. 295; (b) A. J. Banister and J. M. Rawson, in The Chemistry of Inorganic Ring Systems, ed. R. Steudel, Elsevier, Amsterdam, 1992 , p. 323.

2 A. Vegas, A. Pérez-Salazar, A. J. Banister and R. G. Hey, J. Chem. Soc., Dalton Trans., 1980, 1812; H.-U. Hofs, J. W. Bats,

R. Gleiter, G. Hartmann, R. Mews, M. Eckert-Maksić, H. Oberhammer and G. M. Sheldrick, Chem. Ber., 1985, 118, 3781; A. W. Cordes, J. D. Goddard, R. T. Oakley and N. P. C. Westwood, J. Am. Chem. Soc., 1989, 111, 6147; A. J. Banister, M. I. Hansford, Z. V. Hauptmann, S. T. Wait and W. Clegg, J. Chem. Soc., Dalton Trans., 1989, 1705.

3 P. Del Bel Belluz, A. W. Cordes, E. M. Kristof, P. Kristof, S. W. Liblong and R. T. Oakley, J. Am. Chem. Soc., 1989, 111, 9276.

4 A. W. Cordes, R. C. Haddon, R. G. Hicks, R. T. Oakley and T. T. M. Palstra, Inorg. Chem., 1992, 31, 1802.

5 A. W. Cordes, R. C. Haddon, R. T. Oakley, L. F. Schneemeyer, J. V. Waszczak, K. M. Young and N. M. Zimmerman, J. Am. Chem. Soc., 1991, 113, 582.

6 M. P. Andrews, A. W. Cordes, D. C. Douglas, R. M. Fleming, S. H. Glarum, R. C. Haddon, P. Marsh, R. T. Oakley, T. T. M. Palstra, L. F. Schneemeyer, G. W. Trucks, R. Tycko, J. V. Waszczak, K. M. Young and N. M. Zimmerman, J. Am. Chem. Soc., 1991, 113, 3559.

7 A. W. Cordes, R. C. Haddon, R. G. Hicks, R. T. Oakley, T. T. M. Palstra, L. F. Schneemeyer and J. V. Waszczak, J. Am. Chem. Soc., 1992, 114, 1729.

8 R. T. Boeré, R. T. Oakley and R. W. Reed, J. Organomet. Chem., 1987, 331, 161.

9 A. Bondi, J. Phys. Chem., 1964, 68, 441. 